\title{
Sea-ice dynamics in the Weddell Sea in winter
}

\author{
HEINRICH HOEBER \\ Meteorologisches Institut, Universität Hamburg, Bundesstrasse 55, D-2000 Hamburg 13, Germany
}

\begin{abstract}
Observations of ice drift received from an array of ARGOS buoys drifting in the Weddell Sea in winter 1986 are described. Wind and current data are also available, permitting derivation of the complete momentum budget including the internal ice stress computed as residuum. It is shown that the variability of forcing both of the atmosphere and of the ocean is large, and that internal ice stress is not negligible; monthly vector averages amount to about half of the wind and water stresses. Coefficients of shear and bulk viscosity are derived according to Hibler's model of ice rheology; they turn out to be negative occasionally, in particular when small-scale forcing of the atmosphere is large.
\end{abstract}

\section{INTRODUCTION}

Sea ice interacts strongly with adjacent media, i.e. the boundary layers of the atmosphere and the ocean. It greatly modifies the exchange of momentum and heat between the ocean and the atmosphere. Modelling these processes ultimately requires a coupled three-media model which includes air, ice and water. However, data describing the dynamic-thermodynamic behaviour of sea ice are sparse, particularly in Antarctic waters where, with some regional exceptions, sea ice melts every spring and forms anew every autumn. Compared to the perennial ice cover of the Arctic, conditions for ice formation are basically different in Antarctica, leading to different mechanical properties of the ice and different response to atmospheric and oceanic forcing. In the southern winter, sea ice extends as far north as $55^{\circ} \mathrm{S}$, and thus contributes to the pronounced asymmetry between the large-scale circulation features of the southern and northern hemispheres. Clearly, such circumstances and their interannual variations are of interest to investigators of the Earth's climate system.

This paper presents data from a network of drifting buoys collected during the Winter Weddell Sea Project (WWSP) of F.S. Polarstern in 1986 with the aim of investigating sea-ice dynamics, in particular the components of the momentum budget. A sufficiently large number of buoys equipped with air pressure sensors, as well as wind and current meters, was available, allowing the derivation of the complete budget including internal ice stress, and the determination of spatial derivatives of divergence and deformation of ice velocity. Thus, the observational prerequisites needed to derive the coefficients of shear and bulk viscosity which represent ice rheology in ice formation models are available; an evaluation of the data to this effect will be presented.

\section{FIELD EXPERIMENT AND FORCING CONDITIONS}

The WWSP was a multidisciplinary research programme in the area of Maud Rise $\left(65^{\circ} \mathrm{S}, 3^{\circ} \mathrm{E}\right)$, focusing on airsea-ice interaction and on biological processes in the Antarctic pack-ice zone in winter. A network of drifting ARGOS buoys was established while the ship worked her way down to the Antarctic coast. The stations were deployed in an area covering roughly $500 \times 700 \mathrm{~km}^{2}$; scales down to $100 \mathrm{~km}$ were resolved. The network configuration on 1 September 1986, together with some fixed Antarctic stations, is shown in Figure 1. A detailed description of the buoys and their sensor performance was given by Hoeber and Gube-Lenhardt (1987). Each station carried sensors for pressure, air temperature, ice temperature, and wind speed and direction, the latter measured at a height of $2.1 \mathrm{~m}$. In addition, four stations were equipped with acoustic current meters at $10 \mathrm{~m}$ depth. Positions provided by the ARGOS system are accurate to $\pm 250 \mathrm{~m}$. Ice-drift velocity was determined by interpolating positions onto the full hour and computing velocity at time $t$ from space increments between time $t-1 \mathrm{~h}$ and $t+1 \mathrm{~h}$. The positional uncertainty mentioned above leads to velocity errors of $\pm 0.05 \mathrm{~m} \mathrm{~s}^{-1}$.

The station network drifted with the ice and was considerably deformed as is shown in Figure 2. Prevailing winds and currents are reflected in this pattern; whereas the northern portion of the network is well within the belt of westerly winds and the Antarctic Circumpolar Current, the southern portion is governed by the return flow of the eastern Weddell Gyre pushing stations towards the north later in the year. Thus, the pattern shows rotation as well as deformation and divergence. From the data, in particular from the relationship between wind and relative current, a good estimate of the 


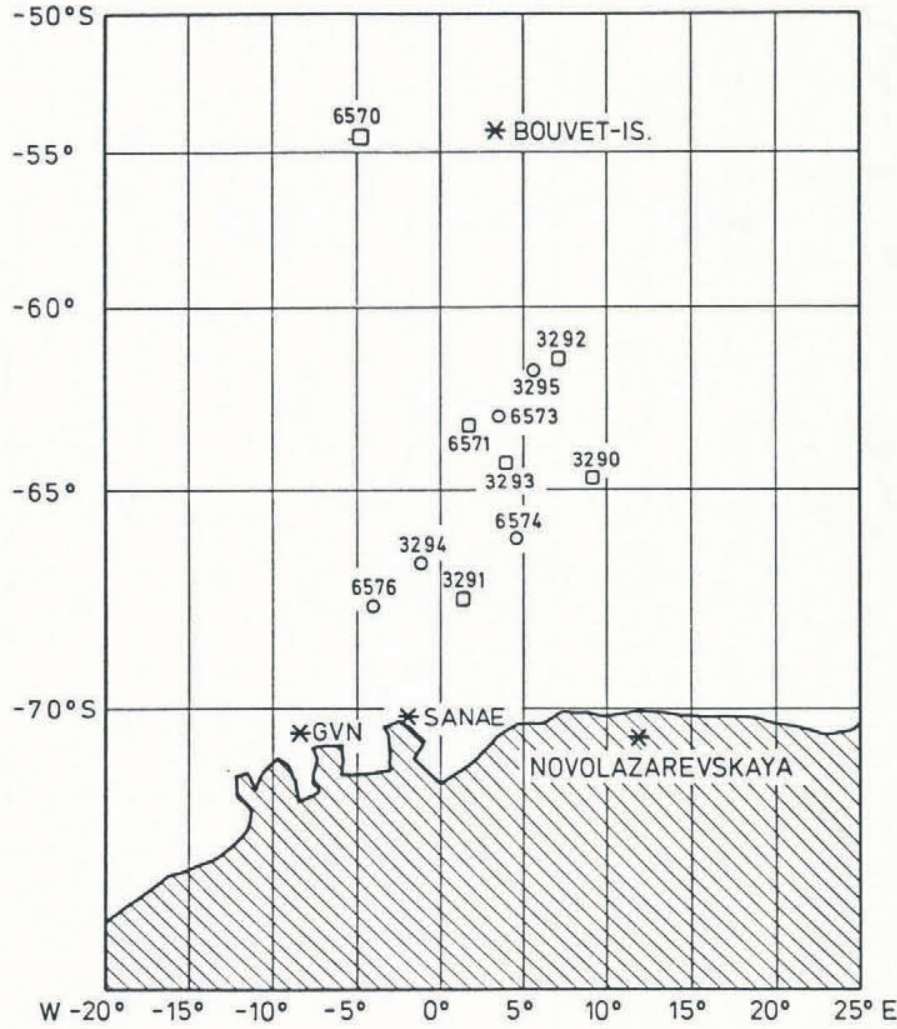

Fig. 1. Station distribution on 1 September 1986. ARGOS buoys are indicated by their station number. Circles denote stations with current meter, squares are stations without current meter (see text). Stars indicate nearby land or island stations.
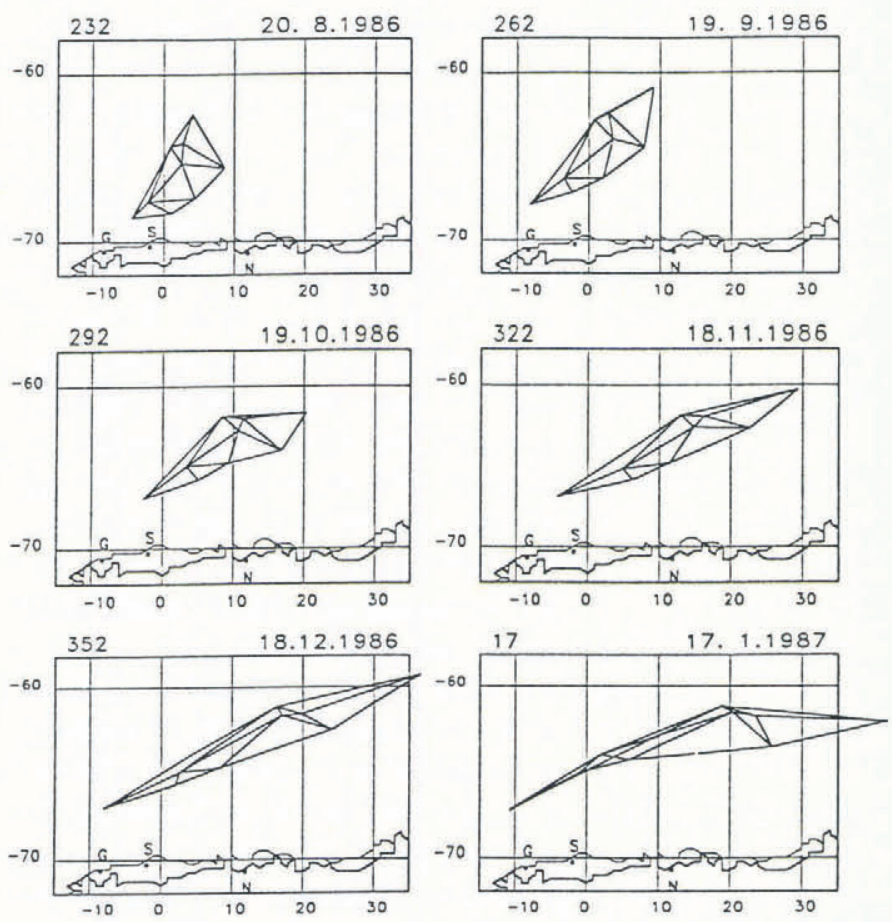

Fig. 2. Network deformation from the day of its first completion in August 1986 to January 1987 when all stations were in open water. date of ice breakup can be made. Ice breakup occurred in early November, with complete ice melt around the middle of December (Hoeber, 1989).

Weather and ice conditions during the WWSP were reported by Rabe (1987) and Wadhams and others (1987), respectively. The weather was characterized by the frequent passage of cyclones over the area. On the whole, the Weddell Sea depression was well established. However, one of the yet unexplained observations was the changing scale of the disturbances, i.e. the variation of the cyclone diameter. Large-scale cyclones developed a wind field more or less homogeneous over the entire buoy network, which consequently created a homogeneous ice-drift field with little deformation. On the other hand, when the cyclones were small, with a diameter of approximately that of the station network itself, deformation, rotation and convergence were large, causing considerable ice pressing and ridging. An example of each case is given in Figure 3 which shows objective analyses of geostrophic wind using the pressure observations of the buoys. This feature also has thermodynamic consequences. For a reasonable prediction of sea-ice behaviour, it is important to understand why and when one case or the other will develop; this, however, is beyond the scope of this paper.
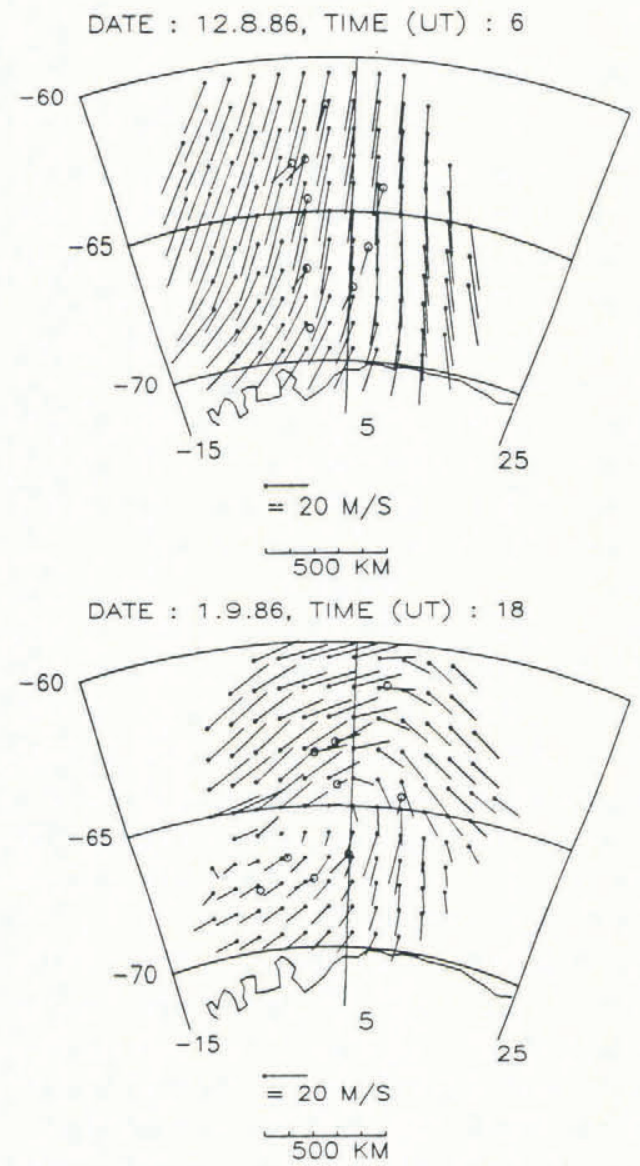

Fig. 3. Objective analyses of geostrophic winds using buoy pressure and wind observations. Examples show flow systems of different scales: (A) large-scale system on $12 \mathrm{Au}$ gust 1986 with homogeneous flow of warm air over the network, (B) small-scale system on 1 September 1986, exhibiting marked velocity gradients over the network. 

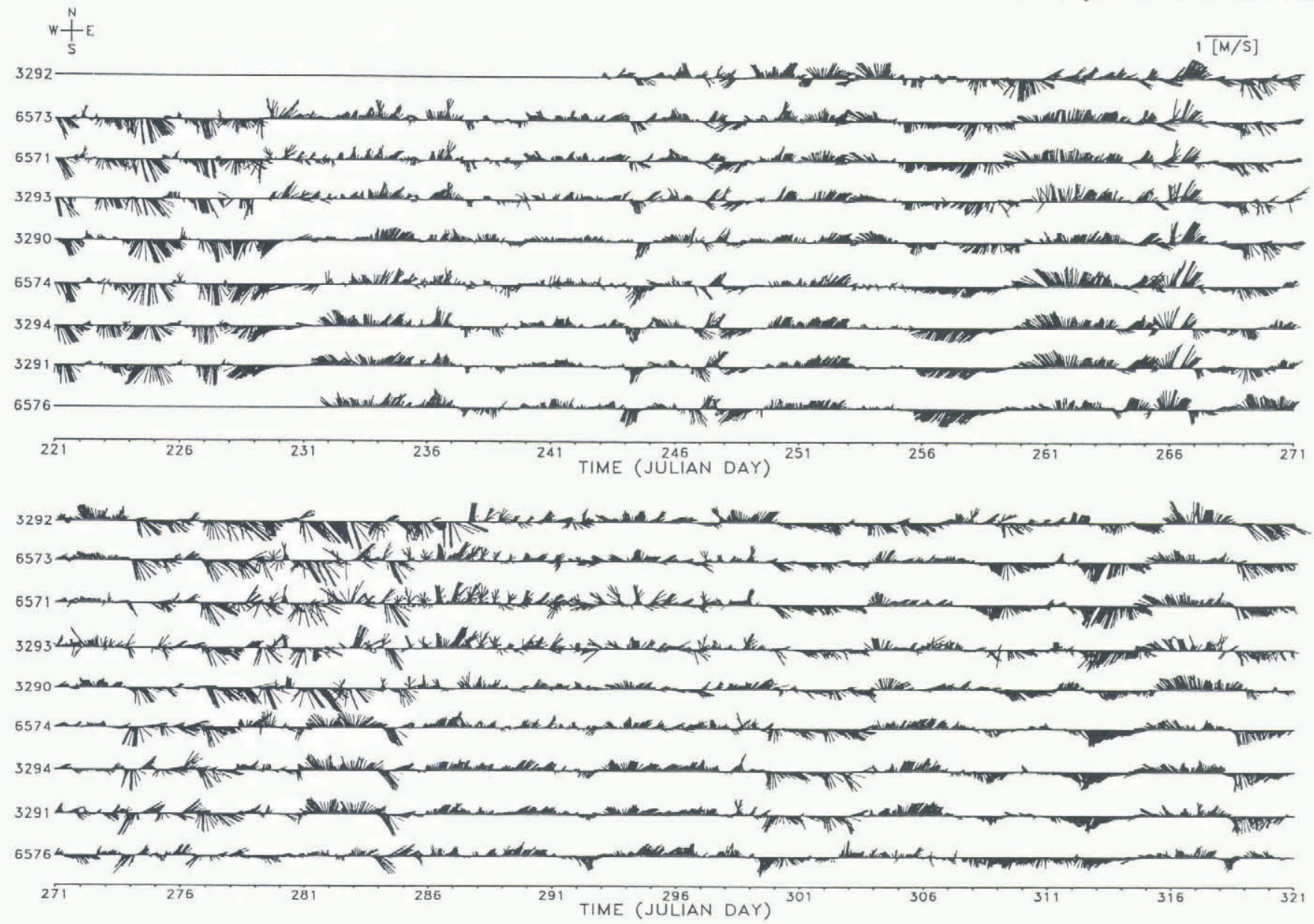

Fig. 4. Hourly series of ice drift velocity vectors from 9 August to 16 November 1986 (day 221 to day 320). Stations are ordered from north to south according to their position at the start of the series. Origin of drift vector is on the line; velocity scale and orientation is given at the top.

Wadhams and others (1987) provide detailed information on ice concentration, thickness and snow cover. Apart from the ice margin, the ice consisted of consolidated pancake ice of about $90 \%$ concentration. Thicknesses of undeformed floes were around 0.4 to $0.6 \mathrm{~m}$ with 0.05 to $0.15 \mathrm{~m}$ of snow cover. Modest ridging was observed - in which case ice thickness increased up to $4 \mathrm{~m}$ - and only a few multi-year ice floes with thicknesses above $8 \mathrm{~m}$ were encountered. Proceeding southward, an insignificant increase of average ice thickness was observed. On the return leg, the thickness at $62^{\circ} \mathrm{S}$ - where the first consolidated ice cover was observed in July - had increased from 0.40 to $0.65 \mathrm{~m}$ in September.

The time series of hourly ice-drift vectors is shown in Figure 4, where stations are ordered according to their position from north to south. Considering the limits given by the time resolution and accuracy of the positional data, there is a number of remarkable features in the dataset requiring explanation. Notice, for instance, the uniformity and high coherence of movements in the area on some days (e.g. days 260 to 268) as opposed to the up to $180^{\circ}$ difference of movements on other days (e.g. days 230 and 281 to 282 ). This feature is a reflection of the driving force (i.e. the atmospheric flow field above the ice) which, as described above, was uniform over the entire network in some cases and not in others.
The forcing by oceanic currents is also highly variable. Figure 5 shows current vectors averaged over $10 \mathrm{~d}$ periods in August, derived from three-hourly data; numbers give per cent steadiness, defined as the ratio of the magnitude of the mean current vector to the average speed of the current. We observe an average speed of up to $20 \mathrm{~cm} \mathrm{~s}^{-1}$, particularly high at the northernmost stations where the

$$
\text { 1. - 10. Aug. 11. - 20. Aug. }
$$$$
\text { 21. - 30. Aug. }
$$

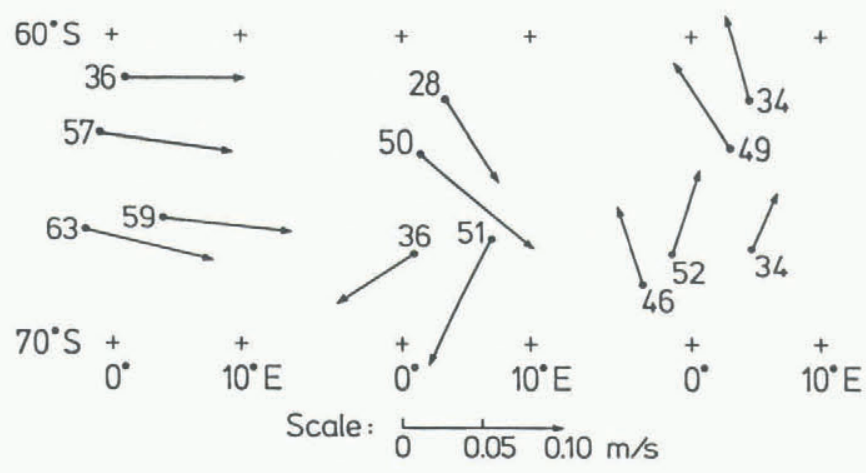

Fig. 5. Average vectors of absolute current for 10 d periods in August 1986. Arrows originate at the station position, numbers give steadiness of the averaged vector in per cent. 
Antarctic Circumpolar Current is well developed. According to the average picture found in the earlier literature (Gordon and others, 1981), our array should lie on the eastern margin of the Weddell Gyre, and thus should show eastward to southeastward currents with perhaps a westward return current close to the continent in the south. This is not confirmed. Instead we find large variance both on short time scales, as is evident from the generally low steadiness, and on the scale of the averaging period. The zonal flow prevailing in the first ten days of August down to $67^{\circ} \mathrm{S}$ is replaced by a cyclonic eddy passing through the area during the second and third $10 \mathrm{~d}$ period. Inertial oscillations are abundant; the ice reacts by following the periodic movement at times (see Fig. 4, days 230 to 235 at station 6571 and more frequently later in the year). We conclude that current data appear to be a necessary prerequisite for a sensible interpretation of ice drift and the momentum budget.

Wind speed at $2 \mathrm{~m}$ height ranged from calm to $20 \mathrm{~m} \mathrm{~s}^{-1}$, relative current speed from 0 to $0.55 \mathrm{~m} \mathrm{~s}^{-1}$. The correlation between wind speed and ice speed relative to the moving water is demonstrated in Figure 6, which shows data of station 6574 (one of the central stations) for the month of August; other stations look rather similar. The relative ice speed is $2 \%$ of the wind speed. This figure, sometimes referred to as the wind factor, increases significantly in September and October (i.e. with the same atmospheric forcing, the ice moves faster in spring than in winter). The wind factor is related to the ratio of drag coefficients of the air-ice and ice-water interface, implications of which are discussed in the following section.

\section{THE MOMENTUM BUDGET}

\section{OF THE SEA-ICE COVER}

The momentum budget of an ice-covered water surface has to account for five stress terms which force the ice movement: the wind stress $\left(\boldsymbol{\tau}_{\mathrm{a}}\right)$ at the ice surface, water stress $\left(\tau_{\mathrm{w}}\right)$ at the underside of the ice, Coriolis force (C) acting on the ice mass, gravity force $(\mathbf{G})$ due to

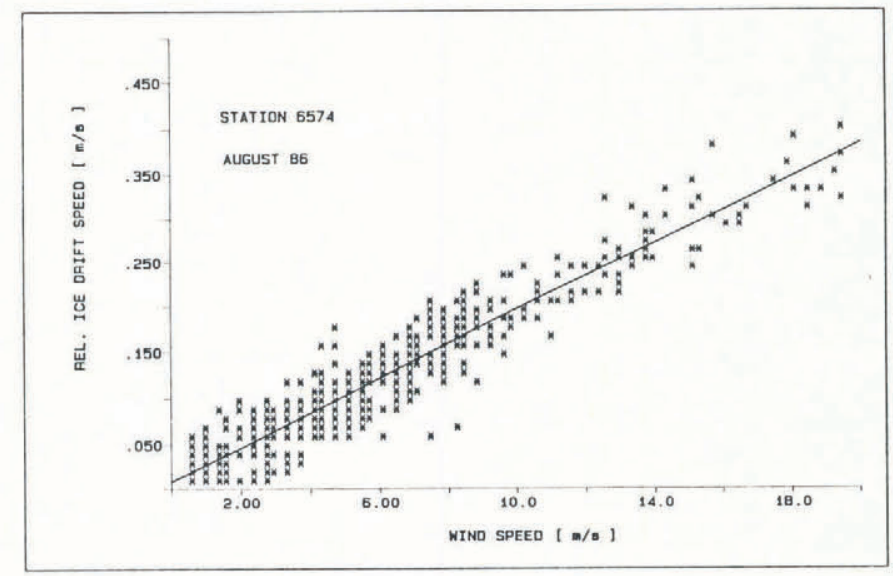

Fig. 6. Regression between wind speed and ice speed relative to the water for August 1986 at station 65\%4. Regression line is $y=$ $0.0188 x+0.0087\left(\mathrm{~ms}^{-1}\right), \mathrm{N}=532$. the tilt of the sea surface and internal ice stress $(\mathbf{F})$. If a balance between these components is not established, inertial forces - accelerations - arise. All of the components can be computed from the observations, assuming that the stresses are proportional to the squared wind and current speed, and that the sea-surface tilt due to a geostrophic current is proportional to the current measured at $10 \mathrm{~m}$ depth. Internal stress $\mathbf{F}$ follows from

$$
\mathbf{F}=\rho_{\mathrm{i}} h_{\mathrm{i}} \frac{\mathrm{d} \mathbf{V}}{\mathrm{d} t}-\left(\boldsymbol{\tau}_{\mathrm{a}}+\boldsymbol{\tau}_{\mathbf{w}}+\mathbf{C}+\mathbf{G}\right),
$$

where $\mathbf{V}=$ ice velocity, $\rho_{\mathrm{i}}=$ ice density, $h_{\mathrm{i}}=$ ice thickness. For the wind stress, an air-ice drag coefficient of 0.0013 was employed. (The parameters necessary for the computations are summarized in Table 1.) The ice-water drag coefficient was determined from the observed wind factor for cases where the free drift condition - no internal stress, no acceleration - was given (Table 1). We note a significant change from midwinter to spring; the August value corresponds to a wind factor of $1.9 \%$ (as in Fig. 6), whereas the October value corresponds to $2.7 \%$. This seasonal change is ascribed to the melting of the sea ice which (a) smoothes the underside of the floes and (b) stabilizes the water column under the ice and thus decreases momentum exchange and friction; the latter effect has been demonstrated by McPhee (1987) using model simulations.

The outcome of the total momentum budget for each station is shown in Figure 7. Progressive vector diagrams are presented through August 1986 for each of the five momentum components. The budget is largely balanced between wind stress and water stress, with Coriolis force and acceleration being minor and internal stress intermediate in importance. We note that much of the detail in the wind stress graph is mirrored in the water stress graph. This apparent symmetry hints at the capability of the ice to react instantaneously to changes in the atmospheric forcing - albeit not always completely, so that a residuum arises because accelerations are small. Internal ice stress cannot be neglected. It becomes less

Table 1. Parameters used in Equation (1) to compute the internal ice stress

Quantity Value Unit

$\begin{array}{lll}\text { air density } & 1.3 & \mathrm{~kg} \mathrm{~m}^{-3} \\ \text { water density } & 1027 & \mathrm{~kg} \mathrm{~m}^{-3} \\ \text { ice density } & 850 & \mathrm{~kg} \mathrm{~m}^{-3} \\ \text { ice thickness } & 0.7 & \mathrm{~m} \\ \text { Coriolis parameter } & -1.32 \times 10^{-4} & \mathrm{~s}^{-1} \\ \text { air-ice drag coefficient } & 0.0013 & \end{array}$

ice-water drag coefficient
August
0.0047
September
0.0030
October
0.0022 


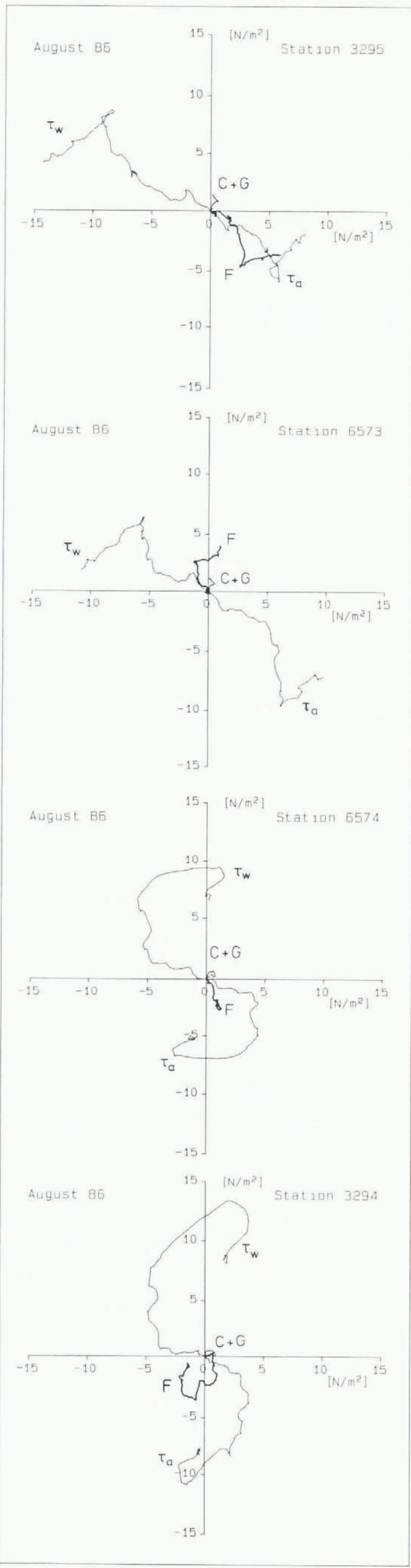

important the deeper the stations are in the ice, in accordance with the fact that the force exerted by internal stress is in general proportional to the horizontal gradient of the deformation tensor; whereas deformation may be large in the interior, its gradient will be smaller both away from the ice margin and away from the coastal zone in the south (Hibler, 1986). September and October 1986 data show essentially the same behaviour.

\section{ICE VISCOSITY}

The basis for deriving shear viscosity $(\eta)$ and bulk viscosity $(\zeta)$ is given by Hibler's model of ice rheology which relates the stress tensor to the strain-rate tensor and to a pressure term, the latter usually being parameterized by ice compactness and ice thickness. From Wadhams and others (1987), we conclude that both thickness and compactness did not exhibit significant large-scale spatial variations in the experimental area, from which we assume that the space derivatives of the pressure term - which enter into computation of the internal stress force in Hibler's system - are negligible. With this simplification and after some rearrangement, it follows from Hibler's equation that

$$
\begin{aligned}
& \frac{\partial}{\partial x}\left(\eta \cdot \operatorname{def}_{1} \mathbf{V}\right)+\frac{\partial}{\partial y}\left(\eta \cdot \operatorname{def}_{2} \mathbf{V}\right)+\frac{\partial}{\partial x}(\zeta \cdot \operatorname{div} \mathbf{V})=\mathbf{F}_{x} \\
& \frac{\partial}{\partial x}\left(\eta \cdot \operatorname{def}_{2} \mathbf{V}\right)-\frac{\partial}{\partial y}\left(\eta \cdot \operatorname{def}_{1} \mathbf{V}\right)+\frac{\partial}{\partial y}(\zeta \cdot \operatorname{div} \mathbf{V})=\mathbf{F}_{y}
\end{aligned}
$$

where $\operatorname{def}_{1} \mathbf{V}=\partial u / \partial x-\partial v / \partial y, \operatorname{def}_{2} \mathbf{V}=\partial v / \partial x+\partial u / \partial y$, and $\operatorname{div} \mathbf{V}=\partial u / \partial x+\partial v / \partial y$. Since the second derivatives of the ice velocity are required in Equation (2), a second-order polynomial in $x$ and $y$ was fitted to the data. With nine stations, this is the highest order possible, leaving three degrees of freedom. The RMS residual between the observed velocity data and the polynomial is generally below $0.10 \mathrm{~m} \mathrm{~s}^{-1}$, i.e. of the same magnitude as the measuring accuracy stated above. Thus, the signal appears to be well defined by the second-order fit, which provides linear $x-y$-dependencies of divergence and deformation, and constant second derivatives in the array.

Divergence is of the order $\pm 10^{-6} \mathrm{~s}^{-1}$ and deformation of the order $2 \times 10^{-6} \mathrm{~s}^{-1}$. Both are one order of magnitude larger than reported by Wadhams and others (1989), who computed divergence and deformation from a large-scale network using four buoys separated by more than $1000 \mathrm{~km}$. Our network has a typical station separation of order $200 \mathrm{~km}$. Hoeber and others (1989) showed, from small-scale observations in the Arctic, that divergence may be as large as $5 \times 10^{-6} \mathrm{~s}^{-1}$, when a $5 \mathrm{~km}$ network is employed. Clearly, spatial derivatives depend on the scale under consideration. Divergence and deformation derived from the WWSP array are typical for the so-called synoptic scale of the atmospheric forcing.

Fig. 7. Progressive vector diagrams for $\mathrm{Au}$ gust 1986 of the components of the momentum budget: air stress, $\boldsymbol{\tau}_{a}$, water stress, $\boldsymbol{\tau}_{w}$, relative Coriolis force, $\mathbf{C}+\mathbf{G}$, and internal ice stress, F. Inertial force is too small to be visible. Bold trace is internal ice stress. Stations are ordered from north to south. 


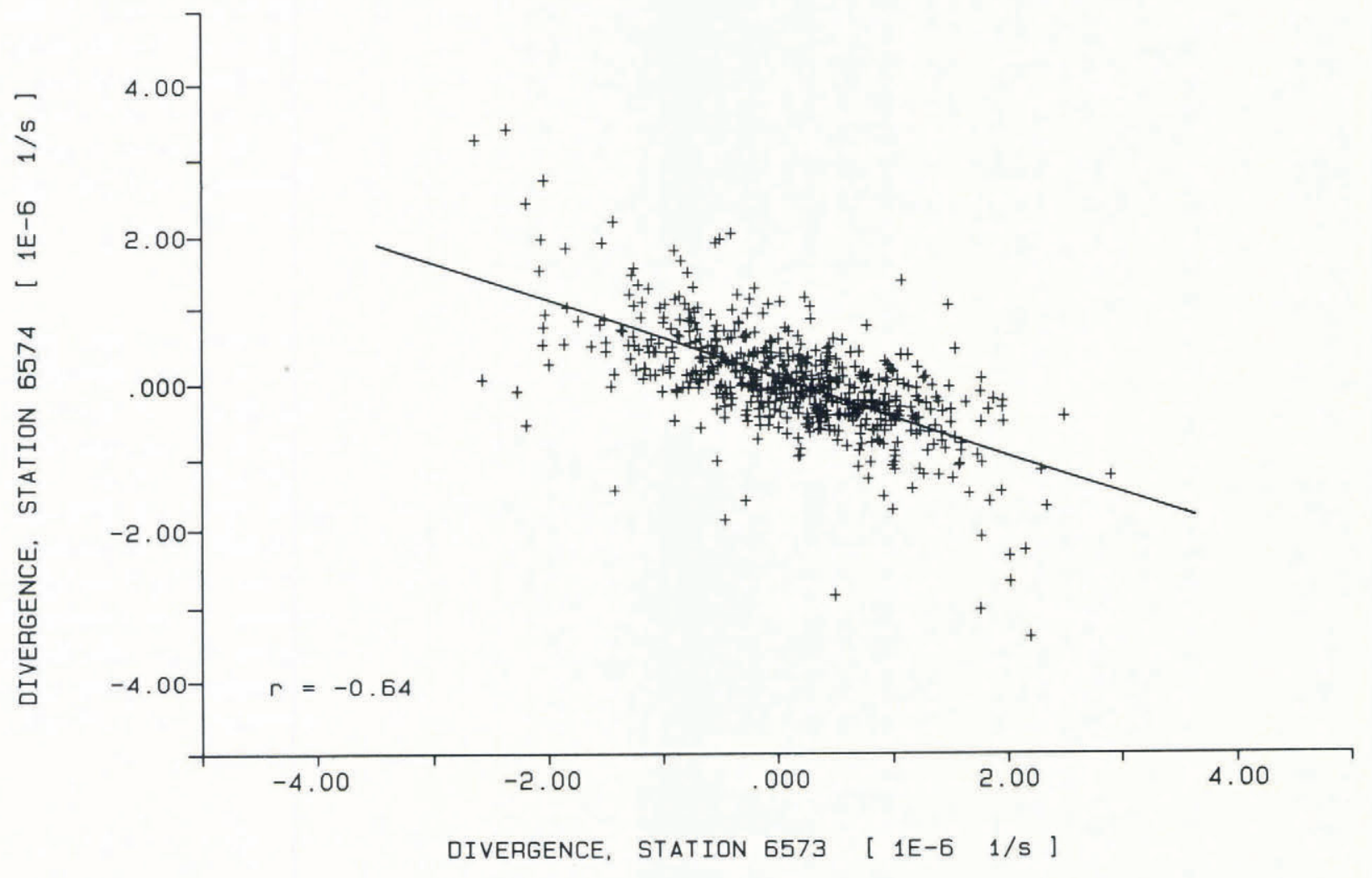

Fig. 8. Relation between divergence of ice drift at station 6573 and station 6574 . Regression line is $y=-0.519 x+0.07 \times 10^{-6}$; correlation coefficient is $-0.64, N=583$.

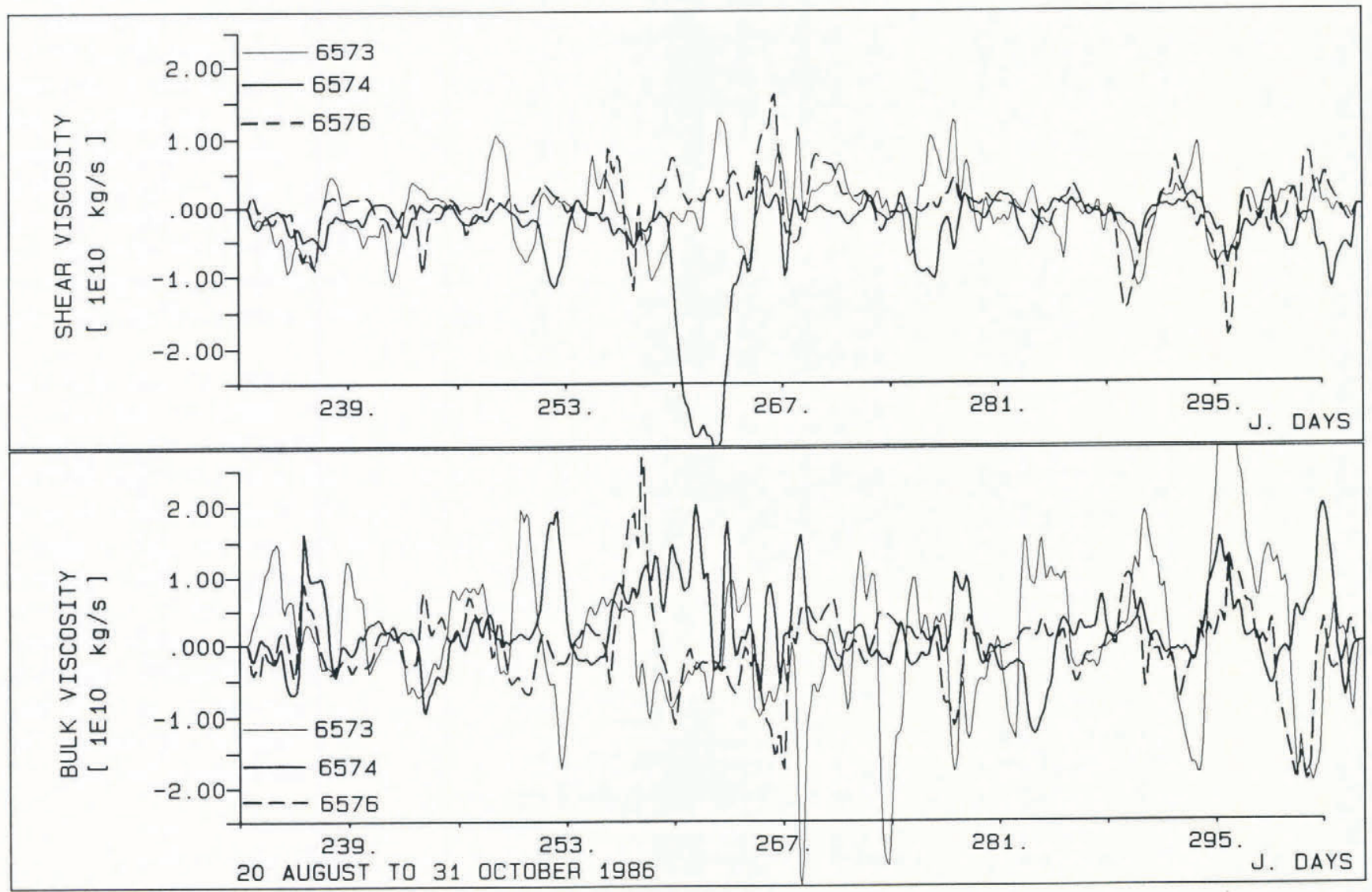

Fig. 9. Shear viscosity, $\eta$, (upper panel) and bulk viscosity, $\zeta$, (lower panel) in units of $10^{10} \mathrm{~kg} \mathrm{~s}^{-1}$ for the three stations - 6573 (thin curves), 6574 (bold curves) and 6576 (dashed curves) - from 20 August to 31 October 1986. 
There is little correlation between the divergence and deformation of the various stations, with one exception (Fig. 8) - the divergence of the northern station 6573 correlates negatively with the divergence of 6574 in the centre (correlation coefficient -0.64). Obviously there is a certain coupling between these stations; the ice in the centre "feels" the movement of the ice in the north some $400 \mathrm{~km}$ away and vice versa. No correlation exists between either of the former two stations and station 6576 in the south, the latter obviously drifting in a decoupled regime (i.e. in the easterly wind regime south of the low pressure belt). On the other hand, deformation shows poor correlation throughout.

The system of Equation (2) contains six unknowns, the two viscosities plus their four spatial derivatives. In order to solve the equation, the three-hourly observations of an extended time period $(1.5 \mathrm{~d})$ were combined. This provides 26 equations for the six unknowns and permits the application of a least-squares variance method which minimizes the length of the difference vector between the computed and the observed internal force $\mathbf{F}$. By this method, it is implied that the viscous properties - the six unknowns - do not vary considerably within a day or two and that the consecutively observed data within such a period are not independent of each other. A solution vector was derived every three hours based on the data of the preceding and following $18 \mathrm{~h}$; the result for the first two unknowns, the shear and the bulk viscosity, is presented in Figure 9.

The variance is considerable, but in view of the limited accuracy of the various observations entering the procedure, much of the variance must be attributed to observational noise. The order of magnitude of $\eta$ and $\zeta$ is between $10^{8}$ and $10^{10} \mathrm{~kg} \mathrm{~s}^{-1}$, and thus is in accordance with values used in ice-drift models. However, negative viscosities are frequently observed, in particular at station 6574 in the week following day 259, where $\eta$ attains values of less than $-3 \times 10^{10} \mathrm{~kg} \mathrm{~s}^{-1}$. This result is independent of the time period chosen to compute a solution vector (when varying this time period from $24 \mathrm{~h}$ to $3 \mathrm{~d}$, the results do not differ essentially). Correlation between the three stations is low, and there is also no dependence of the viscosities on deformation or divergence, as is implied in Hibler's model. There is no particular criterion which would exclude the periods with negative viscosities, such as a particularly large RMS deviation of the second-order fit from the observed drift velocities, for instance.

Negative viscosities are inferred in other problems of fluid dynamics, for example the dynamics of the Gulf Stream or the differential rotation of material in the photosphere of the Sun. They appear when the flux is "counter-gradient", i.e. when an exchange process is at work which lets the small-scale eddies feed the large-scale flow, thereby maintaining gradients instead of trying to reduce them as in "normal" turbulence. An energy input at the small-scale end is, therefore, a necessary prerequisite.

Considering the atmosphere as the main driving agent for sea-ice motion, an analysis of the kinetic energy of the atmospheric flow was made using the geostrophic wind measured by the buoy array. Figure 10 shows the eddy kinetic energy (EKE), i.e. the kinetic energy of

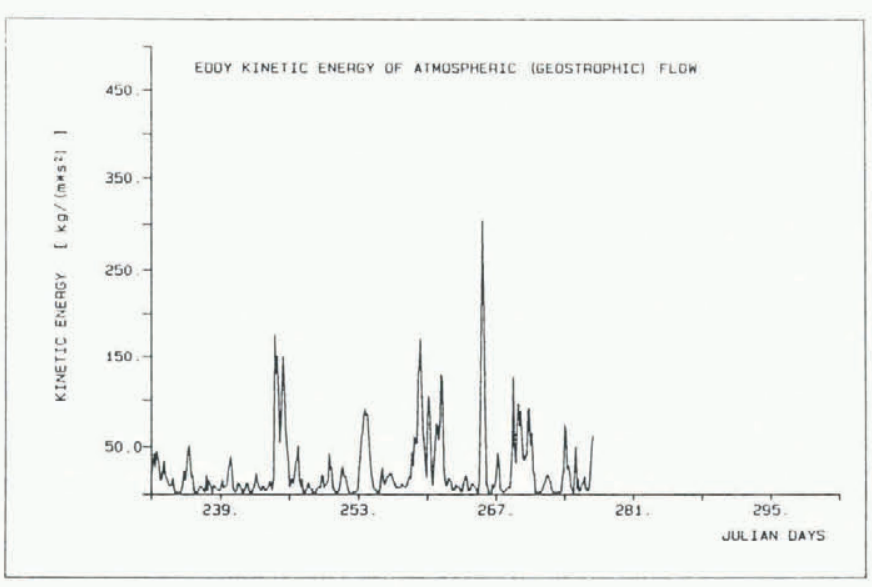

Fig. 10. Eddy kinetic energy of the geostrophic atmospheric flow at meridian $1.2^{\circ} \mathrm{E}$ between latitudes $60^{\circ}$ and $70^{\circ} \mathrm{S}$ from $20 \mathrm{Au}$ gust to 3 October 1986.

the small-scale geostrophic flow deviating from the mean along the meridian of $1.2^{\circ} \mathrm{E}$ between latitudes $60^{\circ}$ and $70^{\circ} \mathrm{S}$ (the time series is limited to day 276, 3 October). The week beginning with day 258 is marked by high EKE for an extended period. In fact, a cyclonic system with a record low pressure $(924 \mathrm{hPa}$, see Hoeber and GubeLenhardt, 1987) was dominating over the array during this time and must have conditioned the ice in an as yet unknown manner to account for the negative viscosity at central station 6574. However, EKE is also high at other days, albeit for shorter periods of time, without a clearly related negative viscosity. The condition of high EKE is, thus, necessary but not sufficient.

\section{CONCLUSIONS}

Observations of sea-ice drift and of the driving atmospheric and oceanic forces around the Antarctic reveal large variability in space and time. A variety of time scales, ranging from the inertial period to the periods which govern the transient eddies both in the atmosphere and the ocean, impinge upon the ice. Combining observations of the components of the momentum budget, which yield internal ice stress as residuum, with observations of the ice drift and its spatial derivatives, allowed the derivation of shear and bulk viscosity coefficients according to Hibler's model. Negative viscosities occur occasionally, but with significant magnitudes and for extended time periods so that observational errors, albeit large, cannot explain them. Rather, it is concluded that - just as in many other fluids - negative viscosity in the moving sea-ice slab cannot be ruled out. To include this finding in sea-ice modelling would impose difficulties; apart from a valid description of the variable forcing fields, it requires a parameterization of the particular process which pre-conditions the ice for the negative viscosity, i.e. for a process which transfers kinetic energy from smaller to larger eddies or to the mean flow. The physical basis for this is, as yet, not available.

Further evidence is, however, required. It would need (1) an array of approximately ten ice drifters to permit determination of second-order spatial derivatives of ice- 


\section{Hoeber: Sea-ice dynamics in Weddell Sea}

drift velocity, (2) observations of the components of the momentum budget, which includes wind and surface current observations and (3) a sampling period short enough to ensure that a number of different realizations of the flow field under quasi-constant viscosity conditions are observed so that Equations (2a) and (2b) can be solved.

Indirect evidence would also be useful. Negative viscosity must be expected where the energy input to the system is significant at the small scale, and where largescale gradients of the resulting flow are maintained for an extended period of time. The information expected from satellites with synthetic aperture radar (SAR) capability could in future improve the database in this respect.

\section{REFERENCES}

Gordon, A.L., D.G. Martinson, and H.W. Taylor. 1981. The wind-driven circulation in the Weddell-Enderby basin. Deep-Sea Res., 28(2A), 151-163.

Hibler, W.D., III. 1986. Ice dynamics. In Untersteiner, N., it ed. The geophysics of sea ice. New York and London, Plenum Press, 577-640.

Hoeber, H. 1989. One-year temperature records in the atmospheric surface-layer above sea ice and open water. Boundary-Layer Meteorol., 48, 293-297.

Hoeber, H. and M. Gube-Lehnhardt. 1987. The eastern Weddell Sea drifting buoy data set of the Winter Wed- dell Sea Project (WWSP) 1986. Ber. Polarforsch., 37.

Hoeber, H., P. Gudmandsen, H. Zhang, and H. Tüg. 1989. A comparison on different scales of direct and satellite-derived observations of ice velocity in the Fram Strait. Proceedings of the 9th EARSeL Symposium, July 1989, Espoo, Finland. Luxemburg, Commission of the European Communities, 123-128.

McPhee, M.G. 1987. A time-dependent model for turbulent transfer in a stratified oceanic boundary layer. $J$. Geophys. Res., 92(C7), 6977-6986.

Rabe, W. 1987. Weather and synoptic situation during Winter Weddell Sea Project 1986 (ANT V/2), July 16-September 10, 1986. Ber. Polarforsch., 40.

Wadhams, P., M.A. Lange, and S.F. Ackley. 1987. The ice thickness distribution across the Atlantic sector of the Antarctic ocean in midwinter. J. Geophys. Res., 92(C13), 14,535-14,552.

Wadhams, P., C.B. Sear, D.R. Crane, M.A. Rowe, S.J. Morrison, and D.W.S. Limbert. 1989. Basin-scale ice motion and deformation in the Weddell Sea during winter. Ann. Glaciol., 12, 178-186.

The accuracy of references in the text and in this list is the responsibility of the author, to whom queries should be addressed. 